\title{
A Supervisão de Estágio da Licenciatura no IB-USP: Ensino por Investigação e Pesquisa
}

\author{
Maria Elice Brzezinski Prestes*, Rosana Louro Ferreira Silva e Daniela Lopes Scarpa \\ Instituto de Biociências da Universidade de São Paulo \\ * Autora para correspondência: eprestes@ib.usp.br
}

\begin{abstract}
RESUMO
A habilitação em licenciatura do curso de Ciências Biológicas do Instituto de Biociências da USP tem passado por constante aprimoramento desde que implantada a nova estrutura curricular em 2007, em resposta à adequação ao Programa de Formação de Professores da USP de 2004. Dentre as principais ações implementadas, destacam-se as atuais disciplinas relacionadas à supervisão das cem horas de estágio nas escolas-campo a cargo do IB-USP. Foram criadas duas disciplinas, Estágio Supervisionado em Ensino de Biologia e Estágio com Pesquisa em Ensino de Biologia, permitindo não apenas a efetiva realização do total de horas nas escolas-campo de estágio, como, mais especialmente, o desenvolvimento e a implementação de práticas de intervenção baseadas no ensino por investigação, bem como de práticas de intervenção acompanhadas de um exercício de pesquisa na área de educação científica. As iniciativas têm resultado em cumprimento bastante satisfatório dos objetivos previstos do processo de ensino-aprendizagem dos alunos.
\end{abstract}

Palavras-chave: Estágio Supervisionado; Ensino por Investigação; Estágio com Pesquisa.

\begin{abstract}
The teacher formation in the Course of Biological Sciences of the Institute of Biosciences of USP has undergone constant improvement since the new curriculum was implemented in 2007, in response to the USP Teacher Training Program (2004). Among the main actions, it is worth highlighting the current disciplines related to the supervision of the 100h internship at the IB-USP internship camp schools. Two disciplines were created, "Supervised Internship in Biology Teaching" and "Internship with Research in Biology Teaching". Such disciplines allow not only the effective realization of the total number of hours of internship in schools, but more especially the development and implementation of intervention practices based on inquiry teaching, as well as intervention practices accompanied by a research exercise in the area of scientific education.. The initiatives have resulted in a very satisfactory fulfillment of the students teaching-learning objectives.
\end{abstract}

Keywords: Supervised Internship; Inquiry Teaching; Internship with Research.

Entre os principais desafios impostos à formação de professores de qualquer nível de ensino, destaca-se a superação da justaposição mecânica de disciplinas pedagógicas e de formação específica, assim como da segmentação entre disciplinas da licenciatura e atividades de estágio. Considerando ações com vistas a vencer tais limitações, o Programa de Formação de Professores da Universidade de São Paulo (PFP) promoveu o compartilhamento de responsabilidades da formação docente entre a Faculdade de Educação (FE) e as unidades que oferecem licenciaturas (USP, 2004).
Objetivando avançar na superação desses desafios, e como em outros cursos da universidade, foi promovida a reforma curricular no curso de Ciências Biológicas, bacharelado e licenciatura, do Instituto de Biociências (IB). A nova grade do curso, de ingresso único para as duas habilitações, implantada em 2007, foi pautada pela flexibilização curricular, com um núcleo básico e um núcleo avançado (cada núcleo podendo ser cursado em dois anos no período integral e três anos no período noturno). O núcleo básico passou a ser composto por disciplinas obrigatórias comuns à licenciatura e ao bacharelado. O núcleo avançado foi estruturado 
por meio de disciplinas optativas, que, no caso da licenciatura, em 2016, passaram a ser exclusivamente de modalidade livre. De caráter específico e caracterizando o aprofundamento do ensino em diferentes subáreas das ciências biológicas, esse arranjo disciplinar possibilitou ampliação significativa do leque de opções aos alunos.

Segundo o compartilhamento de responsabilidades que o PFP estabeleceu entre a Faculdade de Educação e as unidades de formação específica, diversas iniciativas foram estabelecidas na reformulação curricular implantada em 2007. Aqui será discutido unicamente aquele conjunto de ações que se sucederam para o amadurecimento do atual modelo de supervisão de estágios dos licenciandos. O PFP determinara que as quatrocentas horas de estágio previstas na legislação fossem compostas de trezentas horas alocadas em disciplinas da Faculdade de Educação e cem horas nas unidades específicas. As discussões para a implantação do estágio no IB foram no sentido de criar uma identidade própria ao estágio desenvolvido na unidade que não se sobrepusesse, mas complementasse as atividades que já eram exercidas pelos licenciandos na FE.

No currículo de 2007, havia sido criada a disciplina Ensino em Biologia, que teve seu primeiro oferecimento em 2009. O objetivo era promover a iniciação dos graduandos nas questões do ensino de Biologia, propiciando um contato mais íntimo com a licenciatura por meio de atuação profissional. A vivência dos licenciandos na escola básica visava ao aprofundamento da transposição didática, das estratégias e metodologias de ensino e da reflexão sobre a realidade do ensino de Ciências e Biologia, principalmente no sistema público brasileiro.

Em 2012, a disciplina foi reformulada e passou a ser intitulada Estágio Supervisionado em Ensino de Biologia (ESEB), de modo a encampar, desde o título, o compromisso com a formação inicial. Os objetivos passaram a ser direcionados à imersão dos licenciandos no cotidiano escolar, por meio de duas formas de atuação supervisionadas pelos docentes do IB e com auxílio de monitores-bolsistas. A primeira delas era a observação sistemática das atividades guiadas pelo professor da escola-campo de estágio em consonância com o plano de ensino desse professor, com o projeto político-pedagógico da escola e com os componentes da cultura escolar que particularizam o ambiente de aprendizagem da escola-campo. A segunda forma de atuação, desenvolvida em estreita colaboração com o professor da escola-campo, era o planejamento e a execução de intervenções educacionais. Um dos esforços maiores da disciplina voltou-se então ao desenvolvimento de intervenções de ensino guiadas por uma abordagem centrada no aluno, isto é, envolvendo um processo de aprendizagem em que o aluno desempenha uma participação ativa, cabendo ao professor, no caso, o licenciando, agir como mediador desse processo.

Inicialmente, a tarefa pareceu dificultosa. Ponderava-se que a tradição de aulas expositivas que os licenciandos costumam trazer da escola básica que frequentaram, assim como de parte, mas não todas, das próprias disciplinas da graduação em curso, seria uma barreira difícil de transpor. Assim, não foi sem alguma surpresa que logo se constatou forte adesão dos licenciandos à proposta da disciplina de ESEB. Não apenas eles se mostraram motivados a buscar estratégias alternativas de ensino, como manifestaram grande criatividade, inventividade e eficiência na preparação de sequências didáticas e materiais de ensino voltados ao protagonismo do aluno.

Outra característica incorporada no ESEB, atendendo à Deliberação CEE 111/2012, foi a utilização intensiva das Tecnologias de Informação e Comunicação (TICs) como recurso pedagógico para o desenvolvimento pessoal e profissional. Ainda em conformidade com a legislação citada, a fim de complementar a formação científico-cultural dos futuros professores, foram estimuladas e sistematizadas a prática de leitura e a produção de textos de diferentes gêneros, relacionados com planejamento de ensino, descrição de atividades, exercícios, relatórios reflexivos e artigos, entre outros.

As reflexões sobre os estágios como eixo central e articulador no curso de formação de professores, sendo indispensáveis à construção de identidades, saberes e posturas do profissional docente, continuaram a ser promovidas no âmbito da Comissão Organizadora de Currículo da licenciatura do IB. 
Em 2013, as especificidades e complementariedade dos estágios foram objeto de discussão que reuniu os docentes do IB com os das disciplinas de Metodologia do Ensino de Ciências Biológicas I e II da FE.

Em 2014, quando o Instituto já contava com seis docentes especialmente contratados para a licenciatura, foi possível um novo avanço visando à otimização das horas efetivas de estágio na escola-campo. A disciplina foi desmembrada em duas, ESEB I, no primeiro semestre, e ESEB II, no segundo semestre, de modo que os licenciandos realizassem cinquenta horas de estágio em cada semestre. Embora numeradas como I e II, as disciplinas atenderam aos princípios da reforma curricular do curso de 2007, não tendo pré-requisitos.

Duas principais razões motivaram esse desdobramento. A primeira delas diz respeito a condições práticas mais favoráveis à efetivação das horas de estágio. Com cinquenta horas por semestre, as horas de presença do licenciando na escola-campo ficam distribuídas em cerca de três horas/semana, possibilitando sua realização em um único período, matutino, vespertino ou noturno. Sobrecarregados com as outras disciplinas e tarefas do curso, tornou-se mais fácil para os licenciandos acomodarem os períodos de observação e regência, bem como as horas de preparação da intervenção didática na Universidade, com os docentes da disciplina e monitores-bolsistas. A segunda e mais importante razão da divisão das disciplinas é a consolidação das duas experiências que já estavam em curso, a saber, o aprofundamento do desenvolvimento de estratégias diferenciadas de ensino e o olhar de pesquisa sobre a prática docente.

Em 2015, essa identidade foi outra vez levada aos nomes das disciplinas que passaram a se chamar Estágio Supervisionado em Ensino de Biologia (ESEB), no primeiro semestre, e Estágio com Pesquisa em Ensino de Biologia (EPEP), no segundo semestre ${ }^{1}$.

Mantidas as diretrizes teóricas e práticas conquistadas nas experiências pregressas, nesse momento, a disciplina de ESEB passou a apresentar uma proposta explícita de estratégias de ensino de ciências por investigação na elaboração coletiva de ati- vidades de intervenção na escola-campo de estágio. O ensino por investigação busca levar o estudante a desenvolver em classe uma investigação científica, que pode ser definida como o "processo pelo qual o conhecimento científico é desenvolvido e, em virtude de convenções e suposições desse processo, o conhecimento produzido necessariamente possui determinadas características inevitáveis" (LEDERMAN, 2006, p. 308). A mais significante característica dessa abordagem é que ela não pretende apenas que os estudantes aprendam sobre investigação científica (o que já é desejável), mas que eles possam dar um passo além e efetivamente se tornem capazes de fazer investigação científica em sala de aula. Considera-se que elaborar e aplicar intervenções didáticas baseadas no ensino por investigação nas escolas públicas campo de estágio é uma oportunidade para os licenciandos avaliarem as possibilidades e limitações reais de estratégias que permitem uma interação efetiva dos estudantes com os objetos de conhecimento e com seus pares, ao mesmo tempo que ampliam a compreensão sobre aspectos da natureza da ciência.

Além disso, a disciplina de ESEB permanece abordando subsídios teóricos sobre as necessidades e desafios da realidade escolar e suas demandas, análise de documentos curriculares oficiais, discussão de questões como a alfabetização científica e os processos de avaliação. A intenção é aproximar as discussões teóricas das possibilidades práticas que o licenciando observa, analisa e vivencia na sua experiência de estágio ao longo do semestre.

Por sua vez, a disciplina de EPEB teve condições mais favoráveis ao desenvolvimento aprofundado do olhar de pesquisa sobre a prática docente. A disciplina fornece subsídios teóricos e metodológicos para que os licenciandos possam fazer exercício de pesquisa em seus estágios. Com isso, passou a responder a um dos desafios da formação inicial de professores que é o da sensibilização dos licenciandos para a possibilidade de atuação como professor pesquisador e/ ou como pesquisadores da área de ensino. Consolidando o estágio também como campo de produção de conhecimento e a pesquisa como um método de formação, a disciplina objetiva desenvolver a postura de professor pesquisador, a partir da discussão, 
desenvolvimento, aplicação e análise de estratégias investigativas no contexto escolar. Para tanto, são aprofundados a abordagem qualitativa adotada nas pesquisas em educação e seus métodos de coleta e análise de dados. São também exploradas, dependendo dos interesses de investigação de cada grupo de licenciandos, algumas linhas de pesquisa em ensino, tais como o papel da motivação e da emoção no processo de ensino-aprendizagem, educação ambiental, investigação de concepções alternativas, investigação de concepções sobre natureza da ciência, aulas práticas, estudo de interações discursivas, entre outras.

Paralelamente, a disciplina mantém a abordagem de subsídios teóricos que permitem tomar a sala de aula na perspectiva sociocultural, considerando o papel da linguagem, da dinâmica de interações e das diferentes modalidades didáticas na mediação docente. A disciplina trabalha também os sistemas externos de avaliação, realizando estudos de caso e análise das situações das avaliações externas de cada escola-campo, sob a perspectiva de integrar seus achados com a proposta de pesquisa sobre a prática desenvolvida pelos estagiários.

Considera-se que essas perspectivas têm se somado para contribuir com uma formação de professores articulada tanto com a realidade das escolas como com as indicações atuais da pesquisa em ensino de ciências e formação de professores. Dessa forma, o estágio curricular se torna um momento de práxis, ou seja, "atividade teórica de conhecimento, fundamentação, diálogo e intervenção na realidade" (PIMENTA \& LIMA, 2010, p. 45). Destacamos, ainda, que tal perspectiva de estágio, articulada à produção de conhecimento, é considerada pela literatura da área como uma das práticas inovadoras na formação de professores, indicando que a conceituação de professor pesquisador está intimamente associada à de profissional crítico reflexivo e que tal articulação propicia condições para o desenvolvimento de um profissional autônomo e colaborativo (ANDRÉ, 2016).

\section{Considerações Finais}

No âmbito deste relato, as conclusões expressam a percepção geral das equipes docentes ${ }^{2}$. Diversos 140 fatores têm contribuído para um aumento no número de alunos que se formam na licenciatura do IB, como o oferecimento de disciplinas voltadas à formação docente desde o início do ciclo básico, a contratação de docentes da área de ensino, ações diversificadas no Laboratório de Licenciatura (LabLic), o desenvolvimento de pesquisa na área, a participação do IB no Programa Institucional de Bolsas de Iniciação à Docência da USP ${ }^{3}$, o oferecimento de disciplinas variadas na modalidade de optativas livres. A esses fatores, certamente se somam as modalidades de estágio diferenciado aqui relatadas, contribuindo para a formação focada na autonomia intelectual do professor.

As duas disciplinas de estágio supervisionado do IB têm oferecido a construção de um espaço coletivo de produção de saberes e práticas, baseado na integração entre os professores da universidade, estudantes de licenciatura, monitores da disciplina e os próprios professores da educação básica. A participação dos licenciandos tem sido marcada, para a maioria deles, por expressivo envolvimento e entusiasmo durante os cursos. Além disso, os resultados apresentados à classe pelos grupos de trabalho, como nos seminários de observação e nos seminários de intervenção com pesquisa, bem como nos relatórios finais, em sua grande maioria, têm alcançado elevado nível de avaliação pelas equipes docentes.

Por fim, destacam-se nas disciplinas aspectos da chamada "inovação educacional", ainda que se leve em conta a polissemia do termo (SEPÚLVEDA \& ALMEIDA, 2016). Por um lado, as disciplinas desenvolvem-se a partir de normas e políticas públicas externas à escola, além de perspectivas teóricas tais como a do ensino por investigação e da formação do professor pesquisador, caracterizando a denominada "inovação regulatória" (VEIGA, 2003, apud SEPÚLVEDA \& ALMEIDA, 2016). Mas as ações desenvolvidas não são estritamente regulatórias na medida em que os licenciandos fazem um diagnóstico da realidade da escola e definem, conjuntamente com o professor, a série, a classe e o conteúdo que será trabalhado no estágio, bem como dialogam sobre as estratégias de ensino e recursos instrucionais 
a serem adotados. Embora ainda se possa ampliar a articulação entre as práticas educativas e a realidade educacional, por meio de parceria que vá além do contato com o professor que participa do projeto e estabeleça diálogo com toda a comunidade escolar, pode-se considerar que, em alguma medida, ESEB e EPEB aproximam a prática de estágio do sentido de uma "inovação emancipatória" (Idem, ibidem).

\section{Notas}

1 Em 2012 e 2013, quando era uma disciplina única, houve, respectivamente, um total de 53 e 55 alunos matriculados no integral e noturno. Com a criação de duas disciplinas para o estágio, o número total de alunos matriculados no integral e noturno passou para 89 em 2014, 111 em 2015 e 110 em 2016.

2 Resultados de pesquisa sistemática sobre as inovações alcançadas por disciplinas da licenciatura do IB-USP foram apresentados em outros trabalhos, como sobre a pesquisa como eixo articulador do estágio (SILVA et al., 2016) e sobre o papel da pesquisa na formação do professor na disciplina de Introdução ao Ensino de Biologia (SILVA et al., 2012a, 2012b; SPELTA et al., 2012).

3 O PIBID é programa promovido pela Capes e que tem a participação de dezessete licenciaturas da USP. No IB, nos anos de 2015 a 2017, o programa conta com a participação de dois docentes da universidade, quatro professores da educação básica e 24 alunos bolsistas de iniciação à docência.

\section{Referências Bibliográficas}

ANDRÉ, M. "Formar o Professor Pesquisador para um Novo Desenvolvimento Profissional". In: ANDRÉ, M. (org.). Práticas Inovadoras na Formação de Professores. Campinas, SP: Papirus, 2016, pp. 17-34.

LEDERMAN, N. G. "Syntax of Nature of Science within Inquiry and Science Instruction". In: FLICK, L. B. \& LEDERMAN, N. G. Lederman (eds.). Scientific Inquiry and Nature of Science: Implications for Teaching, Learning, and Teacher Education. Dordrecht: Springer, 2006, pp. 301-317.
PIMENTA, S. G. \& LIMA, M. S. L. Estágio e Docência. 6. ed. São Paulo: Cortez, 2010.

SEPULVEDA, C. \& ALMEIDA, M. Pesquisa Colaborativa e Inovações Educacionais em Ensino de Biologia. Feira de Santana, BA: UEFS Editora, 2016.

SILVA, J. R. S.; NUNES, F. P. B.; SPELTA, L. M. P. B.; PRESTES, M. E. B. \& URSI, S. "Ensino por Pesquisa: Análise de uma Proposta para Estudantes do Curso de Ciências Biológicas". Revista Electrónica de Enseñanza de las Ciencias (Reec), vol. 11, n. 2, 2012 (a), pp. 253-272.

; SAITO, L. G.; TOWATA, N.; PRESTES, M. E. B.; SANO, P. \& URSI, S. "Concepções dos Estudantes de Ciências Biológicas sobre Prática Docente e Pesquisa em Ensino: um Estudo de Caso na Universidade de São Paulo". MOREIRA, M. A.; SAHELICES, C. C. \& VILLAGRÁ, J. M. Anais do IV Encontro de Investigação em Ensino de Ciências. Porto Alegre: UBU, UFRGS, PIDEG, IENGI, PPGEnFis, 2012(b), pp. 259-274.

SILVA, R. L. F.; PRESTES, M. E. B.; BELAUNDE, C. Z.; MARTINS, G.; SILLES, B. \& PEROZZI, C. G. A. "A Pesquisa como Eixo Articulador do Estágio Supervisionado no Curso de Licenciatura em Ciências Biológicas". III Congresso Nacional de Formação de Professores e XIII Congresso Estadual Paulista sobre Formação de Educadores. Promovido pela Pró-Reitoria de Graduação e Reitoria da Unesp. Águas de Lindoia, SP, de 11 a 13 de abril de 2016 .

SPELTA, L. M. P. B.; NUNES, F. P. B.; SILVA, J. R. S.; URSI, S. \& PRESTES, M. E. B. "A Pesquisa-Ação na Prática Docente na Disciplina Introdução ao Ensino de Biologia do Curso de Ciências Biológicas do Instituto de Biociências da Universidade de São Paulo". Revista Brasileira de Pesquisa em Educação em Ciências, vol. 12, 2012, n. 2, pp. 71-92.

USP/PRÓ-REITORIA DE GRADUAÇÃO. Programa de Formação de Professores. São Paulo, 2004.

VEIGA, I. P. A. "Inovações e projeto político pedagógico: uma relação regulatória ou emancipatória?" Cadernos CEDES, Campinas, v. 23, n. 61, pp. 267-281, dez. 2003. In: SEPULVEDA, C. \& ALMEIDA, M. Pesquisa, Colaborativa e Inovações Educacionais em Ensino de Biologia. Feira de Santana, BA: UEFS Editora, 2016. 